RAD Conference Proceedings, vol. 3, pp. 213-219, 2018

ISSN 2466-4626 (online) | DOI: 10.21175/RadProc.2018.45

www.rad-proceedings.org

\title{
BILIRUBIN-RIBOFLAVIN MUTUAL INTERACTION IN METHANOL UNDER CONTINUOUS UV IRRADIATION REGIME
}

\author{
Jelena S. Stanojević ${ }^{*}$ Dragan J. Cvetković, \\ Jelena B. Zvezdanović, Ljiljana P. Stanojević, Dejan Z. Marković $†$
}

University of Niš, Faculty of Technology, Leskovac, Serbia

\begin{abstract}
The aim of the present study was to consider bilirubin (BRB) and riboflavin (RFL) mutual interaction in methanol solution under continuous $U V-A$ and $U V-B$ irradiation regime. Continuous irradiations of samples were performed in a cylindrical photochemical reactor "Rayonet", with 10 symmetrically placed lamps having the emission maximum at $300 \mathrm{~nm}(U V-B)$ and $350 \mathrm{~nm}(U V-A)$. The rate of BRB and RFL photodegradation along with simultaneous products formation, as a function of UV exposure time, was followed by combining UV-VIS absorption measurements with RP-HPLC analysis. The compounds were separated by gradient elution with mobile phase A (formic acid, o.1\% water solution) and B (formic acid, o.1\% methanol solution). According to the results obtained, $B R B$ degradation in the absence of RFL was almost 22 times and 9 times slower in comparison to its degradation observed in BRB-RFL mixture under continuous $U V-A$ and $U V-B$ irradiation, respectively. Moreover, BRB degradation in BRB-RFL mixture under anaerobic conditions was almost 24 times and 16 times slower in comparison to the degradation in aerobic conditions under $U V-A$ and $U V-B$ light, respectively. The latter observation suggests that presence of ROS species contributes to $U V$-induced BRB degradation. These experiments provide the indirect proof of $B R B$ acting as Type II sensitizer because of the fact that ${ }^{1} \mathrm{O}_{2}$ produced by RFL mediates BRB irreversible degradation giving rise to dipyrrole methanol adducts as typical products obtained via Type II mechanism.
\end{abstract}

Key words: Bilirubin, photosensitization, riboflavin, RP-HPLC chromatography, UV irradiation

\section{INTRODUCTION}

The sun emits electromagnetic (EM) radiation in the wavelength range from < $0.1 \mathrm{~nm}$ (gamma radiation), over $\mathrm{X}$-(roentgen) rays, ultraviolet, visible and infrared radiation to $>1 \mathrm{~mm}$ (radio waves) [1]. Sunlight photons permanently reaching the Earth surface consist of infrared $(780 \mathrm{~nm}-1 \mathrm{~mm}) \sim 56 \%$, visible (400-780 nm) $\sim 39 \%$ and ultraviolet (UV) light $(100-400 \mathrm{~nm})$ of $\sim 5 \%$ [2], [3]. Although present in the smallest degree, UV light is the most energetic component belonging to the non-ionizing part of EM spectrum. It is conventionally divided in 3 sub-ranges: UV-A (320-400 nm), UV-B (280-320 nm) and UV-C $(100-280 \mathrm{~nm})$ [4].

Ultraviolet-B radiation (so called burning rays), consisting $\sim 4-5 \%$ of the UV radiation reaching the Earth surface is its most active constituent. The only good property of this component is that it is necessary for vitamin $\mathrm{D}_{3}$ synthesis in the skin. On the other side, UV-B radiation is more genotoxic but less penetrating the skin than UV-A exerting its effects in epidermal skin layer inducing erythema, skin darkening, sunburns etc. [3], [5], [6]. More than $95 \%$ of UV light reaching the Earth surface consists of UV-A rays (so called aging rays) [4], [7]-[9]. Ultraviolet-A radiation is more cytotoxic than UV-B because it reaches dermal skin layers [10], [11].

On the surface of the human skin, sunlight could be reflected, scattered or absorbed. In order to exert biological effects light has to be absorbed by the atoms/molecules in the skin [12].

Photosensitizers are special kind of molecules with the ability to absorb the light energy consequently reaching the excited states through whom they allow chemical reactions which, in their absence, would not occurr. The photosensitizer may or may not change chemically [13]. Most photosensitized reactions take place over a triplet state, so the most effective sensitizers are those that give a long-lived triplet state with high quantum yield [14]. Photosensitized oxidations occur through two competitive mechanisms designated as Type I and Type II [15]. According to Foote's definition Type I mechanism refers to the direct reaction between the excited triplet sensitizer (3Sens) and the substrate (fatty acids, phenolics etc.) producing free radicals via hydrogen abstraction or electron transfer. Type II mechanism implies energy transfer from 3 Sens to molecular oxygen $\left(3 \mathrm{O}_{2}\right)$ i.e. triplet-triplet annihilation, giving rise to extremely electrophilic singlet oxygen $\left({ }^{1} \mathrm{O}_{2}\right)$, which easily oxidizes surrounding biomolecules [16].

*jelena_stanojevic@yahoo.com 
Endogenous photosensitizers belong to the tetrapyrrole group (protoporphyrin IX, uroporphyrin III), flavins (FMN, FAD), and reduced pyridine nucleotides (NADH, NADPH) while exogenous are derived from cosmetics, food additives and drugs such as phenothiazine and non-steroidal antiinflammatory drugs. Most of these agents lead to skin damage [12]

Bilirubin (BRB) is a water insoluble yellowishorange pigment permanently created in healthy adults as a final product of heme catabolism. Its clinical importance is reflected in the fact that $B R B$ accumulation in the blood and extravascular tissues is very often the sign of disease in adults (often liver and bile ducts diseases). On the other side, neonatal hyperbilirubinemia (physiological jaundice) occurs in $60 \%$ of term and $80 \%$ of preterm infants due to their adaptation to extra-uterine conditions. This disorder is often treated by phototherapy, a method that uses blue light energy in order to change the shape and the structure of BRB molecule thus facilitating its excretion [17]-[19].

Riboflavin (RFL, vitamin B2), as a prosthetic group of coenzymes flavin mononucleotide (FMN) and flavin adenine dinucleotide (FAD), has a central role in energy-yielding metabolism of carbohydrates, proteins and lipids [20]. It is widely distributed in food, mainly in the form of FAD. Green, leafy vegetables (especially asparagus, broccoli and spinach), meat (especially beef liver), fat fish (salmon, trout, tuna, herring, mackerel), milk products (milk, cheese - especially cheddar), beer yeast and eggs are rich sources of vitamin B2. Riboflavin is necessary for erythrocytes formation and respiration, antibody production, growth regulation and human reproduction [21].

Structures of riboflavin and bilirubin are shown in Figure 1.

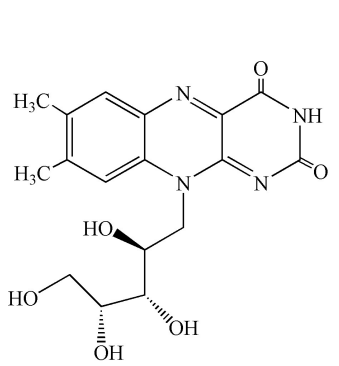

(a)

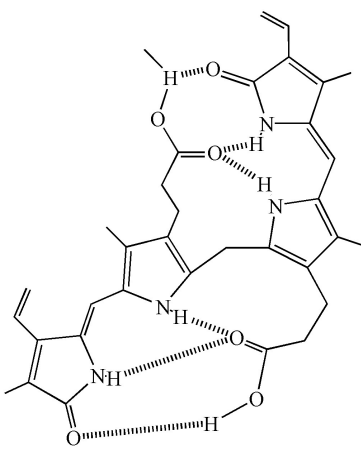

(b)
Figure 1. Structures of riboflavin (a) and bilirubin (b)

The aim of the present study is to consider a mutual interaction of two photosensitizers - BRB and RFL, naturally present in the human skin, in the simplest possible system - methanolic solution, under continuous UV-A and UV-B irradiation regime.
2. EXPERIMENT

\subsection{Sample preparation}

Stock solution of BRB was prepared by dissolving $20 \mathrm{mg}$ of BRB (Fluka AG, Buchs, Switzerland) in 1.5 $\mathrm{ml}$ of ammonium hydroxide (25\%) and then methanol (Ultra Gradient HPLC Grade; J.T. Baker, Deventer, The Netherlands) was added to the final 5 ml. Riboflavin solution was prepared by dissolving $36.7 \mathrm{mg}$ of RFL (98 \%, Alfa Aesar, Karlsruhe, Germany) in $25 \mathrm{ml}$ of 0.01 moldm$^{-3}$ sodium hydroxide (AnalaR NORMAPUR, Leuven, Belgium). Working solutions were made fresh, by diluting the stocks, and stored at $4{ }^{\circ} \mathrm{C}$ until their use, protected from light with aluminum foil (to avoid any photochemical changes). Bilirubin and riboflavin concentration were $1 \times 10^{-4}$ moldm $^{-3}$ in the final methanol solutions for HPLC analysis. All experiments were done at room temperature. The $\mathrm{pH}$ value of the mixture was 9.5.

\subsection{UV-Irradiation}

Continuous irradiations of BRB and RFL (both in the concentration of $\mathrm{c}=1 \times 10^{-4} \mathrm{moldm}^{-3}$ ) separately as well as in the mixture in methanol, in aliquots of 2.5 $\mathrm{ml}$, were performed in cylindrical photochemical reactor "Rayonet" (Southern New England Ultraviolet Co., Connecticut, USA), with 10 symmetrically placed lamps with emission maximum at $350 \mathrm{~nm}$ (UV-A) and $300 \mathrm{~nm}$ (UV-B). The samples were irradiated in quartz closed cuvettes $(1 \times 1 \times 4.5 \mathrm{~cm})$ placed on rotating circular holder. The total measured energy flux was $13.0 \mathrm{Wm}^{-2}$ and $15.0 \mathrm{Wm}^{-2}$ at $10 \mathrm{~cm}$ distance from UV-A and UV-B lamps. The anaerobic conditions were achieved by bubbling the solutions with nitrogen for at least 10 min prior to irradiation.

\subsection{HPLC chromatography}

The samples were filtered through $0.45 \mu \mathrm{m}$ filter (Thermo Scientific, Germany) and immediately analyzed with Agilent 1100 Series system (Waldbron, Germany), equipped with a binary pump (Agilent 1100 Series), autosampler (Agilent 1200 Series) and DAD detector (Agilent 1200 Series, wavelength range $190-800 \mathrm{~nm}$ ) injecting $20 \mu \mathrm{L}$ into the mobile phase under the flow of $1.0 \mathrm{~cm}^{3} \mathrm{~min}^{-1}$. Mobile phase consisted of $0.1 \%$ formic acid in water (A) and $0.1 \%$ formic acid in methanol (B). Samples were separated into individual components on Zorbax Eclipse Plus C18 column $(4.6 \times 250 \mathrm{~mm}, 5 \mu \mathrm{m})$, thermostated at $25^{\circ} \mathrm{C}$. Solutions of pure BRB and RFL were irradiated separately one by one, as a kind of blank, and analyzed simultaneously with BRB-RFL mixture. Riboflavin was eluted by isocratic elution which consisted of $50 \% \mathrm{~A}$ and $50 \% \mathrm{~B}$ as mobile phase. The linear gradient program that has been applied for BRB analysis was as follows: isocratic run with $70 \% \mathrm{~B}$ for the first 10 minutes, followed by linear gradient to 100 $\% \mathrm{~B}$ to $15^{\text {th }}$ minute, then isocratic run with $100 \% \mathrm{~B}$ to $30^{\text {th }}$ minute, and finally linear gradient to $70 \% \mathrm{~B}$ to $35^{\text {th }}$ minute. Regarding BRB-RFL mixture elution linear gradient used was as follows: isocratic run with $50 \% \mathrm{~B}$ for the first 10 minutes, followed by linear 
gradient to $70 \% \mathrm{~B}$ from $10^{\text {th }}$ to $15^{\text {th }}$ minute, isocratic run with $70 \% \mathrm{~B}$ to $25^{\text {th }}$ minute, linear gradient to 100 $\%$ B from $25^{\text {th }}$ to $29^{\text {th }}$ minute, isocratic elution with $100 \% \mathrm{~B}$ to $40^{\text {th }}$ minute, finally followed by linear gradient to $50 \% \mathrm{~B}$ to $45^{\text {th }}$ minute. All separated components, according to the order of their elution, arrived to DAD detector tuned in wavelengths of their absorption maxima: $450 \mathrm{~nm}$ (BRB), $370 \mathrm{~nm}$ (possible degradation products of BRB), $445 \mathrm{~nm}$ (RFL) and 390 $\mathrm{nm}$ (possible degradation products of RFL).

The values of degradation rate constants were calculated in OriginPro 8 SRo (v8.0724 (B724) OriginLab Corporation, Northampton, MA 01060 USA) software, using a linear regression analysis of an appropriate set of data points.

\section{RESULTS AND DISCUSSION}

The UV-B induced changes (i.e. degradation) of $\mathrm{BRB}$ and RFL in the BRB-RFL mixture as a result of an increased UV-B irradiation periods are shown in Figure 2.

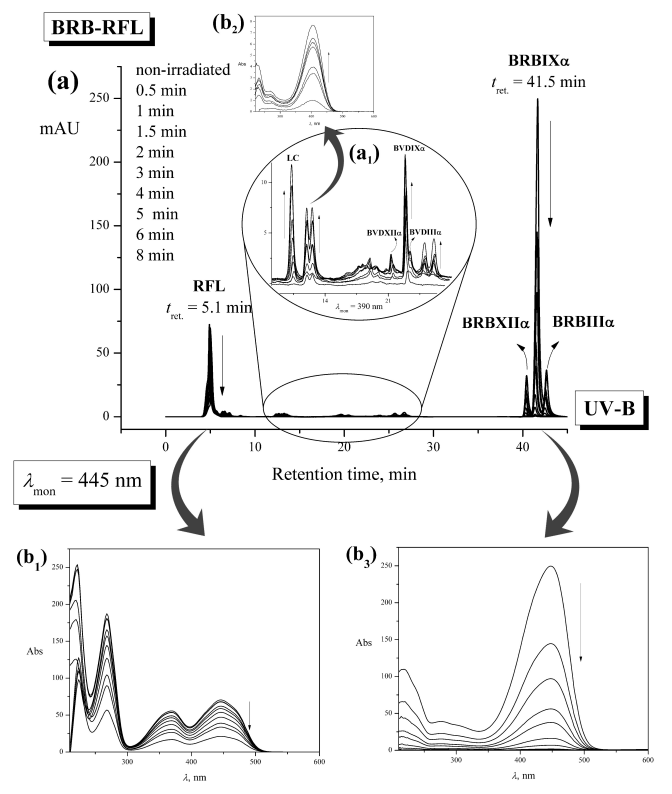

Figure 2. BRB-RFL mixture in methanol. (a)

Chromatograms of non-irradiated and UV-B irradiated BRBRFL mixture, monitored at the wavelength of RFL absorption maximum $\left(\lambda_{\operatorname{mon}}=445 \mathrm{~nm}\right)$. Retention times of RFL and BRB are $5.1 \mathrm{~min}$ and $41.5 \mathrm{~min}$, respectively. (b) Changes of RFL's $\left(b_{1}\right)$ and BRB's $\left(b_{3}\right)$ absorption spectra obtained from the chromatograms recorded at $445 \mathrm{~nm}$ (RFL) and $450 \mathrm{~nm}(\mathrm{BRB})$, respectively, with the increase of continuous UV-B irradiation time. The augmented part of the chromatograms, monitored at $390 \mathrm{~nm}$, focusing on the degradation products $\left(\mathrm{a}_{1}\right)$, especially on dipyrrolic degradation product of $\mathrm{BRB}$, with its absorption spectra change given $\left(\mathrm{b}_{2}\right)$, is shown as the inset.

The peaks eluted at $5.1 \mathrm{~min}$ and $41.5 \mathrm{~min}$ in the chromatograms monitored at $445 \mathrm{~nm}$ were identified as RFL and BRBIXa, respectively. Two smaller peaks, eluted at $40.4 \mathrm{~min}$ (left) and $42.7 \mathrm{~min}$ (right) belong to BRB's isomers - BRBXIIa and BRBIIIa, respectively (Fig. 2a). Simultaneous detection of BRB-RFL mixture at $390 \mathrm{~nm}\left(\right.$ Fig.2a $\left.\mathrm{a}_{1}\right)$ revealed two more major peaks, eluted at $11.0 \mathrm{~min}$ and $24.1 \mathrm{~min}$, identified as biliverdin IXa (BVDIXa) and lumichrome (LC), respectively (Fig. 2a $\mathrm{a}_{1}$. Two smaller peaks, eluted before $\left(t_{\text {ret. }}=21.3 \mathrm{~min}\right)$ and after $\left(t_{\text {ret. }}=23.4 \mathrm{~min}\right)$ BVDIXa, were identified as BVD's isomers, BVDXIIa and BVDIIIa, respectively (Fig. $1 \mathrm{a}_{1}$ ). The identification was based on our previous results (regarding the spectral characteristics of all observed peaks) obtained by UHPLC-ESI-MS analysis of UV-B induced degradation of BRB [22] and RFL [23] in methanolic solution.

The investigation of BRB's degradation in aerobic methanol solution by continuous UV-B irradiation revealed three products: BRB's derivative BVD and two dipyrrolic products [22]. One of the products observed (Product 2, tret. $=2.45 \mathrm{~min}$, eluted under the experimental conditions of ultra high performance liquid chromatography - diode array - electrospray ionization mass spectrometry analysis - UHPLC-ESIMS given in [22]), identified as 4-ethyl-5-\{[4-ethyl-3methyl-2-(oxometiliden)-2H-pyrrole-5-il]methyl\}-3metiliden-3H-pyrrole-2-caroboxylic acid has absorption maximum at $405 \mathrm{~nm}$ [22]. Since the product with the same spectral characteristics, eluted at 12.4 min (Fig. 2b b $_{2}$, was observed in this paper, it is proposed that those two products are identical. Peaks eluted at $12.6 \mathrm{~min}$ and the two small peaks (less polar than BVDIX $\alpha$ ) eluted at $25.1 \mathrm{~min}$ and $26.1 \mathrm{~min}$, having the absorption maximum between $410 \mathrm{~nm}$ and 420 $\mathrm{nm}$, could be also derived from BRB's degradation, having in mind that their area increase with continuous irradiation. Their unambiguous identification will be the aim of our further studies.

The related kinetic plots referring to the RFL's and BRBIXa's degradation are given in Figure 3(a) and 3(b), respectively.
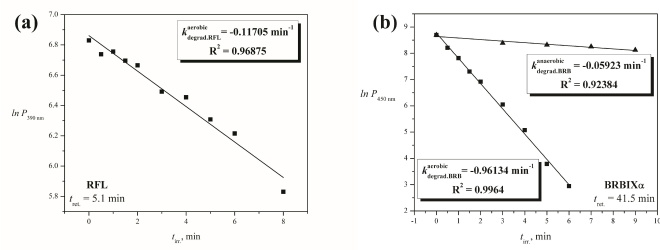

Figure 3. Kinetics of UV-B irradiation-induced bleaching of RFL (a) and BRB (b) in BRB-RFL mixture, followed through a decrease of RFL ( $t_{\text {ret. }}=5.1 \mathrm{~min}$ ) and $\mathrm{BRB}$ ( $\mathrm{t}_{\text {ret. }}=41.5 \mathrm{~min}$ ) peak integrated areas on chromatograms monitored at 390 $\mathrm{nm}$ and $450 \mathrm{~nm}$, respectively, as a result of the increased UV-B irradiation periods ( $\left.\mathrm{t}_{\text {irr. }}\right), \ln \mathrm{P}_{390,450 \mathrm{~nm}}=\mathrm{f}\left(\mathrm{t}_{\text {irr. }}\right)$. The corresponding degradation rate constants under aerobic and anaerobic $\left(\mathrm{k}_{\text {degrad. }}\right)$ and determination coefficients $\left(\mathrm{R}^{2}\right)$ are shown in the plots.

Both RFL and BRB photodegradation proceeds via first-order reaction kinetics.

The degradation rate constants of BRB and RFL, separately and in the mutual mixture, under aerobic 
and anaerobic conditions, during continuous UV-A and UV-B irradiation were shown in Table 1.

The results obtained revealed that $\mathrm{BRB}$ degradation in the absence of RFL was almost 22 times i.e. 9 times slower during continuous UV-A i.e. UV-B irradiation, respectively in comparison to its degradation in the presence of RFL (Table 1). Since BRB's degradation under anaerobic conditions was almost 24 times i.e. 16 times slower in comparison to its degradation in aerobic conditions under UV-A i.e. UV-B irradiation (Table 1) respectively, the presence of Reactive Oxygen Species (ROS) generated by RFL (first of all ${ }^{1} \mathrm{O}_{2}$ ) bear responsibility for its degradation. Namely, photoirradiation of RFL in methanol generates ${ }^{1} \mathrm{O}_{2}$ with the quantum yield of 0.49 [24].

Table 1. Degradation rate constants $\left(\mathrm{k}_{\text {degrad. }}\right.$, $\left.\mathrm{min}^{-1}\right)$ of bilirubin (BRB) and riboflavin (RFL), under aerobic and anaerobic conditions, obtained from the slopes of the $1^{\text {st }}$ order linear plots, ln $\mathrm{P}_{450 / 390} \mathrm{~nm}=\mathrm{f}$ ( tirr.), representing proportional decrease of $\mathrm{BRB}$ and RFL concentrations as a result of the increasing UV-A and UV-B irradiation periods.

$\mathrm{P}_{450 / 390} \mathrm{~nm}$ represents integrated areas of $\mathrm{BRB}$ and $\mathrm{RFL}$ peaks, from the HPLC chromatograms recorded at 450 and $390 \mathrm{~nm}$ (Fig. 2(a)), respectively.

\begin{tabular}{|c|c|c|c|c|c|}
\hline \multicolumn{6}{|c|}{$\mathrm{k}_{\text {degrad., }}$ min $^{-1}$} \\
\hline & & \multicolumn{2}{|c|}{$\begin{array}{c}\text { BRB } \\
t_{\text {ret. }}=42.0 \mathrm{~min}\end{array}$} & \multicolumn{2}{|c|}{$\begin{array}{c}\text { RFL } \\
t_{\text {ret. }}=4.0 \mathrm{~min}\end{array}$} \\
\hline & & UV-A & UV-B & UV-A & UV-B \\
\hline BRB & aerobic & -0.06 & -0.10 & $\times$ & $\times$ \\
\hline RFL & aerobic & $x$ & $\times$ & -0.43 & -0.18 \\
\hline $\begin{array}{l}\text { BRB- } \\
\text { RFL }\end{array}$ & aerobic & -1.38 & -0.96 & -0.14 & -0.12 \\
\hline & anaerobic & -0.06 & -0.06 & -0.30 & -0.17 \\
\hline
\end{tabular}

$x$ - component is not present in the sample

The photochemistry of RFL and its derivatives in aqueous and organic solvents has been a subject of numerous studies in the past few decades [25]-[28]. Generally, RFL's photoreactivity originates from its isoaloxazine ring, which absorbs around $365 \mathrm{~nm}$ and $445 \mathrm{~nm}$. By irradiating with blue (450-495 nm) or UVA light RFL reaches short-lived singlet state ( $\left.{ }^{1} \mathrm{RFL}\right)$ wherefrom it gives long-lived triplet state (3RFL) by very effective intersystem crossing (ISC), with quantum yield of 0.67 . These characteristics classify RFL into the order of powerful photosensitizers. Riboflavin exerts its photosensitizing activity by mixed Type I and Type II mechanisms generating both superoxide anion radical $\left(\mathrm{O}_{2}{ }^{-}\right)$and singlet oxygen $\left({ }^{1} \mathrm{O}_{2}\right)$ [29]. In direct chemical quenching of ${ }^{1} \mathrm{RFL}$ and $3 \mathrm{RFL}$ (both states are active) by different substrates RFL donates or accepts proton/electron giving free radicals (Type I mechanism) which further react with oxygen and other molecules [30]. Various photoproducts were obtained upon RFL exposure to light in methanolic solution. Some of them were formylmethylflavin (FMF), lumichrome (LC), lumiflavin (LF) and carboxymethylflavin (CMF) [23], [26], [28]. FMF, LF and LC are formed from the 3RFL, while ${ }^{1}$ RFL gives rise to the LC. The photochemical reactions involved in products formations are intraand intermolecular photoreduction, intra- and intermolecular photoadditon and intramolecular photodealkylation [26] (Fig. 4).
Having in mind the fact that the redox potential of 3RFL was estimated to be $1.7 \mathrm{~V}$, which is higher in comparison to the redox potential of some important biomolecules (amino acids, proteins, nucleic acids and lipids) 3RFL could, as oxidative specie, induce their photodegradation [31]. According to the redox potential of BRB $(-1.1 \mathrm{~V})$ which is also lower in comparison to the value for $3 \mathrm{RFL}(1.7 \mathrm{~V})$, BRB tends to lose electrons having the possibility to become oxidized in the mutual mixture following the Type I mechanism [32]. In this regard, Knobloch et al. [33] demonstrated that during the photochemical oxidation (and therefore irreversible decomposition) of BRB in an aqueous solution, RFL acted as a reversible electron acceptor, transforming to its leucoform [33]. Non-radical Type II mechanism refers to the physical quenching (i.e. energy transfer) from ${ }^{3} \mathrm{RFL}$ to molecular oxygen $\left({ }^{3} \mathrm{O}_{2}\right)$ giving ${ }^{1} \mathrm{O}_{2}$ [30].

Bilirubin irradiation with light from the wavelength range of $420-460 \mathrm{~nm}$, excites it into singlet state ( $\left.{ }^{1} \mathrm{BRB}\right)$ which, depending on reaction conditions, is further subjected to non-radiative relaxation back to the ground state ( $\left.{ }^{\circ} \mathrm{BRB}\right)$, photoaddition or photooxidation. Bilirubin photooxidation takes place simultaneously by two main paths. The first one is production of biliverdin (BVD) and then by a very slow photochemical reaction giving products with lower molar masses. The second one is direct production of mono- and dipyrolles by Type II mechanism where BRB acts as sensitizer and substrate for ${ }^{1} \mathrm{O}_{2}$ at the same time [34]. The fact that ${ }^{1} \mathrm{BRB}$ gives ${ }^{3 \mathrm{BRB}}$ by ISC with quantum yield of < 0.005 in water ( $\mathrm{pH}$ 9-11) and methanolic solutions classifies it in a group of weak photosensitizers [35]. $3 \mathrm{BRB}$ quenched by $3 \mathrm{O}_{2}$ gives ${ }^{\circ} \mathrm{BRB}$ and very reactive ${ }^{1} \mathrm{O}_{2}$. Fast attack of ${ }^{1} \mathrm{O}_{2}$ on ${ }^{\circ} \mathrm{BRB}$ finally leads to its degradation [36]. Mechanism proposed for BRB's degradation in the presence of RFL is shown in Figure 4.

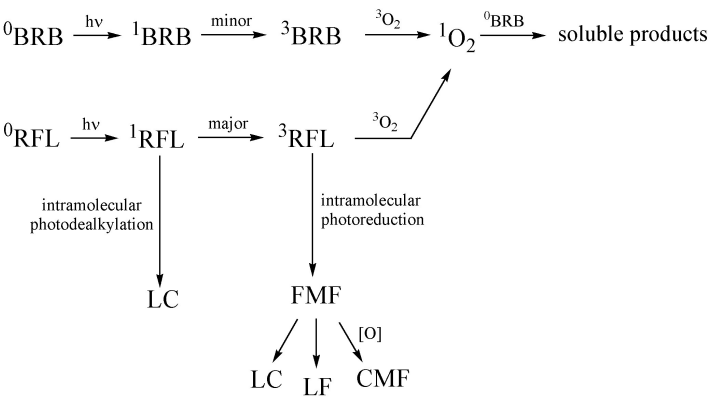

Figure 4. Proposed mechanism of BRB degradation in the presence of RFL as ${ }^{1} \mathrm{O}_{2}$ sensitizer (adapted according to [26] and [36]).

Biliverdin IXa was the only degradation product present in the non-irradiated mixture. Having in mind the fact that BRB could be excited by visible light, BVD appearance could be partly ascribed to BRB's interaction with daily light during sample preparation. However, its area increased significantly during continuous UV irradiation indicating partly Type I mechanism of action. In some of the first papers 
dealing with BRB's photochemistry, BVD was proposed to be the major degradation product giving rise to other, smaller dipyrrolic and monopyrrolic products [37]. Results obtained later revealed that BVD was not the precursor of other degradation products but instead both BRB and BVD decompose to the same products [38], [39].

On the other hand, almost 3 times slower RFL's degradation under UV-A irradiation in the BRB-RFL mixture could be ascribed to the fact that $\mathrm{BRB}$ is one of the most reactive acceptors of ${ }^{1} \mathrm{O}_{2}$. Kinetic studies states that chemical reaction rate of $\mathrm{BRB}$ and ${ }^{1} \mathrm{O}_{2}$ is $3 \times 10^{9} \mathrm{dm}^{3} \mathrm{~mol}^{-1} \mathrm{~s}^{-1}$ and the rate of their physical quenching is $9 \times 10^{8} \mathrm{dm}^{3} \mathrm{~mol}^{-1} \mathrm{~s}^{-1}[36]$.

The experiment supports BRB acting mainly as Type II photosensitizer, i.e. the mediation of singlet oxygen $\left({ }^{1} \mathrm{O}_{2}\right)$ in its irreversible degradation. According to the literature data [34], [36] Type II mechanism of $\mathrm{BRB}$ action is reflected in its slower photooxidation under anaerobic conditions (in this study 24 times i.e. 16 times slower under UV-A and UV-B irradiation, respectively) and faster photooxidation in the presence of photosensitizers that promotes the appearance of ${ }^{1} \mathrm{O}_{2}$ (in this study 22 times i.e. 9 times faster during UV-A i.e. UV-B irradiation, respectively in the presence of RFL).

\section{CONCLUSION}

Photochemical changes induced by UV irradiation were followed by peak area (concentration) decrease of RFL and BRB i.e. peak area increase of their degradation products. The observed changes indicate that there are at least two processes taking place simultaneously - irreversible degradation of RFL and BRB (following the 1st order kinetics) and production of their photodegradation products. Because of the very strong absorption in the UV and VIS regions, RFL's photoexcitation is potentially possible in organs and tissues most exposed to sunlight, first of all skin (especially basal cells and dermis) and eyes (especially the lens), consequently damaging surrounding cell components. Since BRB is an endogenous compound that can be toxic to neonates, its fast "disappearance" in the presence of RFL gives biomedical importance to the presented results.

Acknowledgements: The paper is a part of the research done within the project "Plant and synthetic bioactive products of new generation" no. TR 34012 financed by the Ministry of Education, Science and Technological Development of the Republic of Serbia.

\section{REFERENCES}

1. N. Schade, C. Esser, J. Krutmann, "Ultraviolet B radiation-induced immunosuppression: molecular mechanisms and cellular alterations," Photochem. Photobiol. Sci., vol. 4, no. 9, pp. 699 - 708, Sep. 2005. DOI: $10.1039 / \mathrm{b} 418378 \mathrm{a}$ PMid: 16121280

2. S. González, M. Fernández-Lorente, Y. GilaberteCalzada, "The latest on skin photoprotection,"
Clin. Dermatol., vol. 26, no. 6, pp. 614 - 626, Nov-Dec. 2008.

DOI: 10.1016/j.clindermatol.2007.09.010 PMid: 18940542

3. F. Afaq, "Natural agents: cellular and molecular mechanisms of photoprotection," Arch. Biochem. Biophys., vol. 508, no. 2, pp. 144 - 151, Apr. 2011. DOI: 10.1016/j.abb.2010.12.007 PMid: 21147060

4. A. R. Young, "Acute effects of UVR on human eyes and skin," Prog. Biophys. Mol. Biol., vol. 92, no. 1, pp. $80-85$, Sep. 2006.

DOI: 10.1016/j.pbiomolbio.2006.02.005 PMid: 16600340

5. A. Svobodová, J. Psotová, D. Walterová, "Natural phenolics in the prevention of UV-induced skin damage. A review," Biomed. Pap. Med. Fac. Univ. Palacky Olomouc Czech Repub., vol. 147, no. 2, pp. 137 - 145, Dec. 2003.

PMid: 15037894

6. S. L. Deore, S. Kombade, B. A. Baviskar, S. S. Khadabadi, "Photoprotective antioxidant phytochemicals," Int. J. Phyto. Pharm., vol. 2 no. 3, pp. 72 - 76, May-Jun. 2012. DOI: 10.7439/ijpp.v2i3.501

7. J. Krutmann, "Ultraviolet A radiation-induced biological effects in human skin: relevance for photoaging and photodermatosis," J. Dermatol. Sci., vol. 23, suppl. 1, pp. S22 - S26, Mar. 2000. PMid: 10764987

8. F. Menaa, A. Menaa, J. Tréton, "Polyphenols against skin aging," in Polyphenols in human health and disease, New York (NY), USA: Academic Press, 2013, ch. 63., sec. 6.2, pp. $819-830$.

DOI: 10.1016/B978-0-12-398456-2.00063-3

9. A. Mahns, I. Melchheier, C.V. Suschek, H. Sies, L. O. Klotz, "Irradiation of cells with Ultraviolet-A $(320-400 \mathrm{~nm})$ in the presence of cell culture medium elicits biological effects due to extracellular generation of hydrogen peroxide," Free Radic. Res., vol. 37, no. 4 pp. 391 - 397, Apr. 2003. PMid: 12747733

10. T. Herrling, K. Jung, J. Fuchs, "Measurements of UV-generated free radicals/reactive oxygen species (ROS) in skin," Spectrochim. Acta A. Mol. Biomol. Spectrosc., vol. 63, no. 4, pp. 840 - 845, Mar. 2006. DOI: $10.1016 /$ j.saa.2005.10.013 PMid: 16543118

11. C. A. Brohem et al., "Artificial skin in perspective: concepts and applications," Pigment Cell Melanoma Res., vol. 24, no. 1, pp. 35 - 50, Feb. 2011. DOI: $10.1111 / \mathrm{j} .1755-148 \mathrm{X} .2010 .00786 . \mathrm{x}$ PMid: 21029393

12. G. T. Wondrak, M. K. Jacobson, E. L. Jacobson, "Endogenous UVA photosensitizers: mediators of skin photodamage and novel targets for skin photoprotection," Photochem. Photobiol. Sci., vol. 5, no. 2, pp: 215 - 237, Feb. 2006.

DOI: $10.1039 / \mathrm{b} 504573 \mathrm{~h}$ PMid: 16465308

13. D. Z. Marković, "Kinetika i mehanizam fotosenzibilizovane peroksidacije lipidnih konstituenata biomembrana," Doktorska disertacija, Univerzitet u Beogradu, Prirodnomatematički fakulteti, Fakultet za fizičku hemiju, Srbija, 1990. (D. Z. Marković, "Kinetics and mechanism of photosensitized peroxidation of lipid constituents of biomembranes," Ph.D. dissertation, University of Belgrade, Faculties of Sciences and Mathematics, Faculty for Physical Chemistry, Serbia, 1990.) 
14. C. S. Foote, "Photooxidation," in Phototherapy in the newborn: An overview, Washington (DC), USA: National academy of sciences, 1974, pp. $21-33$. DOI: $10.17226 / 20078$

15. H. P. Lassalle, "Etude des mécanismes du photoblanchiment de la 5,10,15,20-tetrakis(mhydroxyphenyl)bactériochlorine, en solution, in vitro et in vivo," Thèse de doctorat, Université Henri Poincaré-Nancy I, Faculté de Médecine, Nancy, France, 2005. (H. P. Lassalle, "Study of the photobleaching mechanisms of the 5,10,15,20-tetrakis (m-hydroxyphenyl) bacteriochlorin (m-THPBC), in solution, in vitro and in vivo," Ph.D. dissertation, Henri Poincare University-Nancy I, Faculty of Medicine, Nancy, France, 2005.)

Retrieved from: https://tel.archives-ouvertes.fr/tel00378394/document;

Retrieved on: Jun. 24, 2018

16. C.S. Foote, "Mechanisms of Photosensitized Oxidation," Science, vol. 162, no. 3857, pp. $963-970$, Nov. 1968.

DOI: $10.1126 /$ science.162.3857.963

17. S. K. Dey, D. A. Lightner, "Lipid- and water-soluble bilirubins," Monatsh. Chem., vol. 141, no. 1, pp. 101 - 109, Jan. 2010. DOI: 10.1007/s00706-009-0232-5

18. A. F. McDonagh, "Controversies in bilirubin biochemistry and their clinical relevance," Semin. Fetal. Neonatal Med., vol. 15, no. 3, pp. 141 - 147 Jun. 2010.

DOI: 10.1016/j.siny.2009.10.005 PMid: 19932645

19. J. Fevery, "Bilirubin in clinical practice: a review," Liver Int., vol. 28, no. 5, pp. 592 - 605, May. 2008. DOI: $10.1111 / \mathrm{j} .1478-3231.2008 .01716 . \mathrm{x}$ PMid: 18433389

20. G. F. Combs, Jr., "Riboflavin," in The vitamins Fundamental aspects in nutrition and health, 3rd ed., Amsterdam, Netherlands: Academic Press, 2012, ch. 3 pp. $53-54$

Retrieved from: http://197.14.51.10:81/pmb/AGROAL IMENTAIRE/The Vitamins Fundamental aspects in nutrition and health.pdf; Retrieved on: Jun. 24, 2018

21. H. J. Powers, "Riboflavin (vitamin B-2) and health," Am. J. Clin. Nutr., vol. 77, no. 6, pp. $1352-1360$, Jun. 2003.

DOI: $10.1093 /$ ajcn/77.6.1352 PMid: 12791609

22. J. S. Stanojevic, J. B. Zvezdanovic, D. Z. Markovic, "Bilirubin degradation in methanol induced by continuous UV-B irradiation: a UHPLC - ESI-MS study," Pharmazie, vol. 70, no. 4, pp. $225-230$, Apr. 2015.

DOI: $10.1691 / \mathrm{ph} .2015 .4122$

PMid: 26012251

23. J. S. Stanojevic, J. B. Zvezdanovic, D. Z. Markovic, "Riboflavin degradation in the presence of quercetin in methanol under continuous UV-B irradiation: the ESI-MS-UHPLC analysis," Monatsh. Chem., vol. 146, no. 11, pp. $1787-1794$, Nov. 2015 DOI: 0.1007/s00706-015-1561-1

24. J. N. Chacón, J. McLearie, R. S. Sinclair, "Singlet oxygen yields and radical contributions in the dyesensitized photo-oxidation in methanol of esters of polyunsatured fatty acids (oleic, linoleic, linolenic and arachidonic)," Photochem Photobiol., vol. 47, no. 5, pp: $647-656$, May 1988.

25. J. Koziol, "Studies on flavins in organic solvents-II." Photodecomposition of riboflavin in the presence of oxygen," Photochem Photobiol., vol. 5, no. 1, pp. $55-62$, Jan. 1966
DOI: 10.1111/j.1751-1097.1966.tbo5760.x

26. M. A. Sheraz, S. H. Kazi, S. Ahmed, Z. Anwar, I. Ahmad, "Photo, thermal and chemical degradation of riboflavin," Beilstein J. Org. Chem., vol. 10, pp. 1999 - 2012, Aug. 2014. DOI: 10.3762/bjoc.10.208

27. M. Insińska-Rak, A. Golczak, M. Sikorski, "Photochemistry of riboflavin derivatives in methanolic solutions," J. Phys. Chem. A., vol. 116, no. 4, pp. 1199 - 1207, Jan. 2012.

DOI: $10.1021 /$ jp2094593

PMid: 22217187

28. I. Ahmad et al., "Solvent effect on the photolysis of riboflavin," AAPS PharmSciTech., vol. 16, no. 5, pp. $1122-1128$, Oct. 2015. DOI: $10.1208 / \mathrm{s} 12249-015-0304-2$ PMid: 25698084

29. D. R. Cardoso, S. H. Libardia, L. H. Skibsted, "Riboflavin as a photosensitizer. Effects on human health and food quality," Food Funct., vol. 3, no. 5, pp. 487 - 502, May 2012.

DOI: $10.1039 /$ c2fo10246c PMid: 22406738

30. P. F. Heelis, "The photophysical and photochemical properties of flavins (isoalloxazines)," Chem. Soc Rev., vol. 11, no. 1, pp. $15-39,1982$.

DOI: $10.1039 / \operatorname{cs} 9821100015$

31. C. Y. Lu et al., "Generation and photosensitization properties of the oxidized radical of riboflavin: a laser flash photolysis study," J. Photochem. Photobiol. B: Biol., vol. 52, no. 1-3, pp. 111 - 116, Oct. 1999. DOI: 10.1016/S1011-1344(99)00111-6

32. M. Boopathi, M. Subbaiyan, "Oxidation and estimation of bilirubin by using carbon microelectrode," Indian J. Chem. Sec. A., vol. 38A, no. 12, pp. 1239 - 1244, Dec. 1999.

Retrieved from: http://hdl.handle.net/123456789/161 34 ; Retrieved on: Dec. 3, 2018

33. E. Knobloch, R. Hodr, J. Herzman, V. Houdkova, "Function of flavins in photolysis of bilirubin in vitro," Collection Czechoslovak Chern. Commun., vol. 47, no. 5, pp. $1514-1522,1982$. DOI: $10.1135 / \operatorname{cccc} 19821514$

34. R. Bonnett, J. C. M. Stewart, "Photo-oxidation of bilirubin in hydroxylic solvents: propentdyopent adducts as major products," J. Chem. Soc., Chem. Commun., no. 10, pp. 596-597, 1972. DOI: $10.1039 / \mathrm{C}_{39720000596}$

35. G. Agati, F. Fusi, "New trends in photobiology (invited review). Recent advances in bilirubin photophysics," J. Photochem. Photobiol. B., vol. 7, no. 1. pp. 1 - 14 Sep. 1990. PMid: 2125072

36. C. S. Foote, T. Y. Ching, "Chemistry of singlet oxygen. XXI. Kinetics of bilirubin photooxygenation," $J . A m$. Chem. Soc., vol. 97, no. 21, pp. 6209 - 6214, Oct. 1975. PMid: 1176727

37. C. H. Gray, A. Kulczycka, D. C. Nicholson, "The photodecomposition of bilirubin and other bile pigments," J. Chem. Soc. Perkin 1, vol. 3, pp. $288-294,1972$. PMid: 5065591

38. D. A. Lightner, "In vitro photooxidation products of bilirubin," in Phototherapy in the newborn: An overview, Washington (DC), USA: National academy of sciences, 1974, pp. 34- 55 .

Retrieved from: https://www.nap.edu/read/20078/ch apter/1;

Retrieved on: Jun. 24, 2018

39. D. A. Lightner, D. C. Crandall, "Biliverdin photooxidation. In vitro formation of 
Stanojević et al., Bilirubin-riboflavin mutual interaction in methanol, RAD Conf. Proc., vol. 3, 2018, 213-219

methylvinylmaleimide," FEBS Lett., vol. 20, no. 1, pp. $53-56$, Jun. 1972.

PMid: 11946380 